\title{
Adolescent Onset of Localized Papillomatosis, Lymphedema, and Multiple Beta-Papillomavirus Infection: Epidermal Nevus, Segmental Lymphedema Praecox, or Verrucosis? A Case Report and Case Series of Epidermal Nevi
}

\author{
Pooja Kadam ${ }^{a}$ Janne Rand ${ }^{a}$ Peter Rady ${ }^{\text {-e }}$ Stephen Tyring ${ }^{\text {c-e }}$ \\ Jan Stehlik ${ }^{g}$ Monica Sedivcova ${ }^{g}$ Dmitry V. Kazakov ${ }^{g}$ Kathy Ray ${ }^{f}$ \\ Jerome Hill $^{f}$ Richard Agag ${ }^{b} \quad$ J. Andrew Carlson ${ }^{a}$

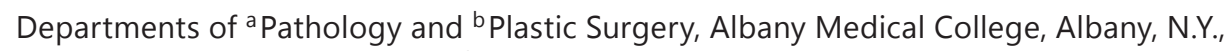 \\ Departments of ${ }^{\mathrm{c}}$ Dermatology, ${ }^{\mathrm{d}}$ Microbiology/Medical Genetics and ${ }^{\mathrm{e}}$ Internal Medicine, \\ University of Texas Health Science Center, Houston, Tex., and ${ }^{\mathrm{f} C a p i t a l}$ District Dermatology, \\ Glenmont, N.Y., USA; ${ }^{9}$ Department of Pathology, Medical Faculty in Pilsen, \\ Charles University, Pilsen, Czech Republic
}

\section{Key Words}

Epidermal nevus · Human papillomavirus · Lymphedema · Elephantiasis · Blaschko's lines ·

GATA2 - GJC2 · HRAS · KRAS · Congenital lymphedema

\begin{abstract}
Herein, we report the case of a 12-year-old female who noted the recent onset of an oval, circumscribed, $10-\mathrm{cm}$ papillomatous plaque affecting the thigh and vulva that showed histologic signs of lymphedema without evidence of secondary lymphedema. The sequencing of genes associated with a delayed onset of lymphedema or epidermal nevi (EN) - GATA2 and GJC2, and HRAS and KRAS, respectively - showed wild-type alleles. Polymerase chain reaction for human papillomavirus (HPV) DNA demonstrated infections with 15 HPV genotypes. Evidence of productive HPV infection, HPV capsid expression, and cytopathic changes was detected. At the 6-month follow-up, no evidence of recurrence was found after complete excision. The analysis of a consecutive series of $91 \mathrm{EN}$ excision specimens revealed that $76 \%$ exhibited histologic evidence of lymphostasis. Notably, multiple acrochordon-like EN, which most closely
\end{abstract}

This study was presented at the XXXIV Symposium of the International Society of Dermatopathology, Florence, Italy, on September 28, 2013. 
resembled this case, showed similar signs of localized lymphedema. The late onset and evidence of lymphedema favors the diagnosis of congenital unisegmental lymphedema. However, the clinical findings and epidermal changes point to the diagnosis of EN. Moreover, localized verrucosis also accurately describes this patient's cutaneous findings. Based on the above evidence, we postulate that an abnormal development of lymphatics may play a primary role in the pathogenesis of some types of EN and facilitate productive HPV infection.

(C) 2014 S. Karger AG, Basel

\section{Introduction}

Herein, we present an unusual case of tardive onset of an ostensible epidermal nevus (EN) that shows the typical findings of keratinocytic EN but also concomitant findings of localized primary lymphedema that has progressed to elephantiasis. Regional verrucosis also accurately describes the plaque. To determine whether this combination of histopathologies (lymphedema and papillomatosis) was happenstance or a common occurrence in EN, we examined a consecutive series of EN, discovering that signs of lymphostasis were frequent and abundant in the common types of EN. In addition, multiple human papillomavirus (HPV) genotypes, mostly beta-PV, were detected in lesional tissue associated with HPV cytopathic alterations and HPV capsid antigen expression, all signs of productive HPV infection and supportive of an interpretation of verrucosis. Based on the aforementioned, we postulate that the papillomatous and verrucous epidermal hyperplasias found in some EN and in elephantiasis are the consequence of local immune suppression caused by lymphatic failure, which permits the progression of latent to productive HPV infection.

\section{Case Report}

\section{Clinical Findings}

A 12-year-old, healthy adolescent female sought dermatologic consultation for an asymptomatic, papillomatous groin lesion recently noted while showering a week or more previously. The patient had recently received an HPV vaccine and blamed this vaccine for the onset of the plaque. She recalled having had a pimple in the region 1 month previously and reported having had hand warts as a child. She denied any sexual activity and did not report any episode of trauma, irritation, rash such as hidradenitis, or infection at this site or elsewhere. On examination, the plaque was $10 \mathrm{~cm}$ in its greatest diameter and exhibited soft, gray-tanned papules and polyps that formed a mosaic pattern with a textured surface. The plaque did not cross the midline (fig. 1). The clinical differential diagnosis included EN, HPV infection, and acanthosis nigricans. A biopsy was taken.

\section{Histopathologic Findings}

A 2-mm punch biopsy showed papillated epidermal hyperplasia that mimicked that of a seborrheic keratosis in conjunction with dermal edema and dilated lymphatic spaces. About $10 \%$ of the spinous layer keratinocytes exhibited perinuclear halos, some of which surrounded angulated, hyperchromatic nuclei, which fulfilled Meisels and Fortin's criteria for HPV infection [1]. Focally, clusters of epidermodysplasia verruciformis (EV)-like cells were present (round or oval, balloon-like spinous keratinocytes with a granular, grayish, or clear cytoplasm, usually located in the spinous layer in isolation or grouped in nests [2]). In addition, hyperkeratosis and hypergranulosis similar to that of verruca plana (fine-to-large, irregular, clumped keratohyaline granules $[3,4]$ ) were found underlying a basket weave stratum corneum. Due to the 
Fig. 1. Unilateral segmental primary elephantiasis versus multiple acrochordon-like EN. This 12-year-old female presented with an asymptomatic oval 9-cm plaque of the inner thigh-buttock-vulva that shows irregular but well-defined borders and a cobblestone surface that is formed by multiple soft-brown fibroepithelial polyps and scattered red, firm polypoid papules.
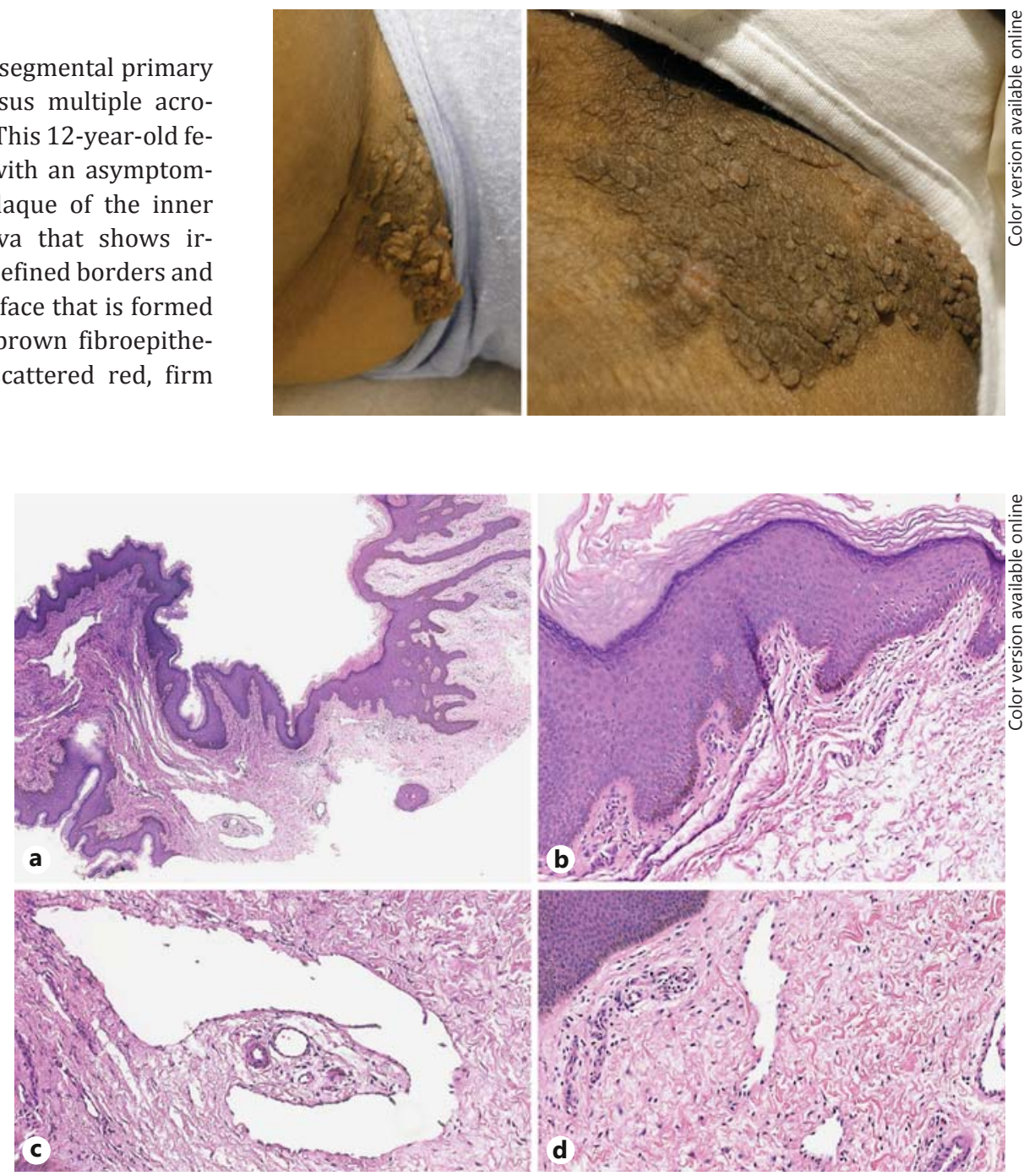

Fig. 2. Lymphedematous fibroepithelial polyp. The second biopsy (shave biopsy) demonstrated a histology of chronic lymphedema [6]. a Marked papillomatous epidermal hyperplasia accompanied by an edematous and fibrous dermis. $\mathbf{b}$ Features similar to an old wart with rounded papillations, slight inward bending of the rete, and hypergranulosis in the dells between papillations. c 'Promontory sign'; in this case, a small artery and vein protruding into a large lymphangiectasis. d Dermal edema, fibroplasia, dilated lymphatic vessels, and uniformly distributed stromal cells characteristic of chronic lymphedema.

presence of these focal HPV cytopathic effects, tissue sections were tested for high-risk HPV types (i.e. 16, 18, 31, 33, 35, 39, 45, 51, 52, 56, 58, and 66) by in situ hybridization; no high-risk HPV DNAs were detected (the methods have previously been described [5]).

As the biopsy specimen was small and the distinction between EN and HPV infection could not be confidently made, a second biopsy (shave biopsy) was performed 2 weeks later. This second biopsy exhibited similar changes of papillated epidermal hyperplasia with focal and regional HPV cytopathic changes. However, it also showed more extensive lymphatic dilation coupled with dermal edema, fibroplasia (an increase in fine, widely spaced dermal collagen bundles), and uniformly distributed spindle and dendritic cells (fig. 2). This constellation of histologic features is diagnostic of localized lymphedema (elephantiasis) [6]. 


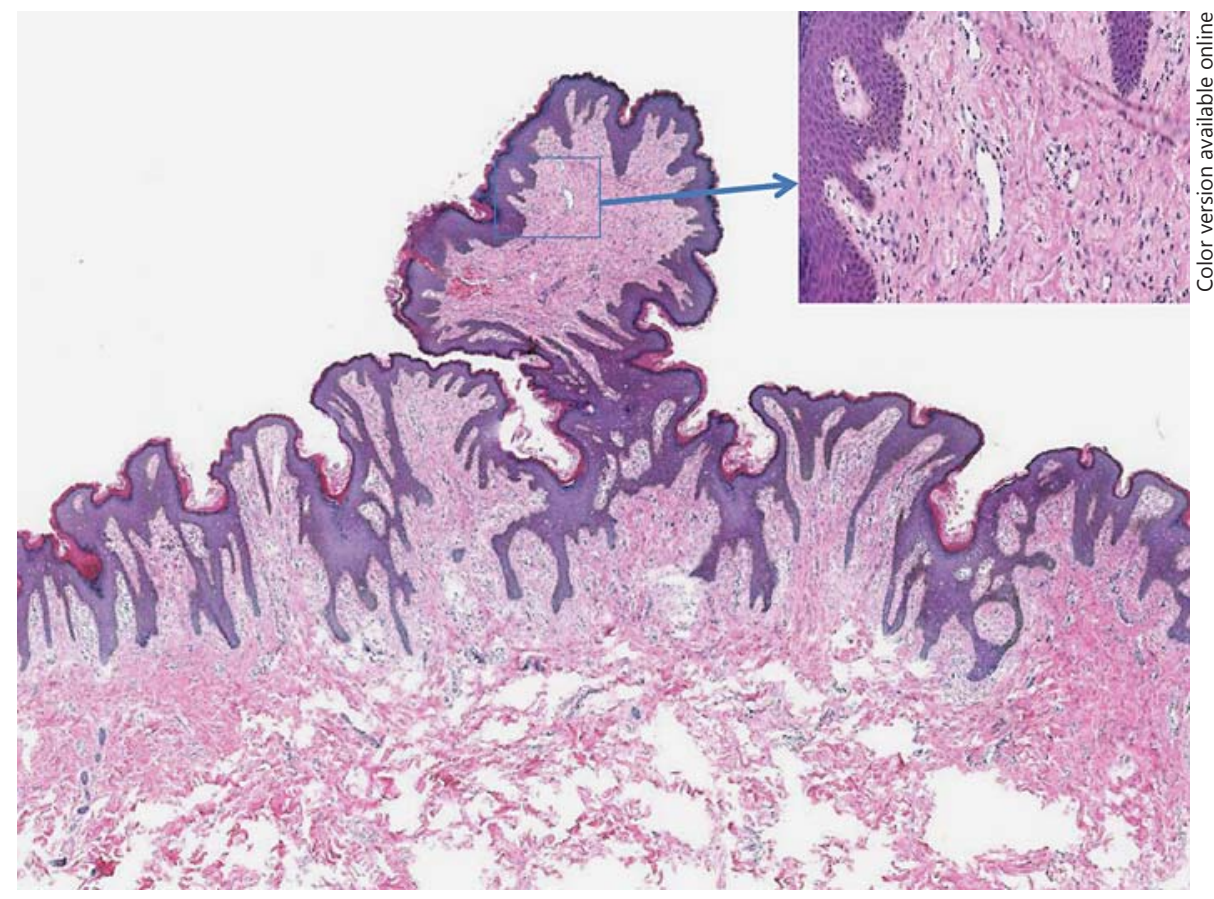

Fig. 3. Seborrheic keratosis-like EN. In addition to features of acrochordon-like EN, the excision specimens showed seborrheic keratosis-like changes with formation of horn pseudocysts and acanthosis [16]. Inset Stromal change of dermal edema, fibroplasia, dilated lymphatic vessels, and uniformly distributed stromal cells.

Due to the circumscription, size, and location, the following management options were recommended: observation, laser ablation, or local excision. The patient and family did not return to the dermatology clinic, but 13 months later, they consulted a plastic surgeon and agreed to have the papillomatosis plaque excised (after deliberation of the risks including recurrence and scarring with vulvar contracture). An excision with a V-Y flap was performed with normal margins of $2 \mathrm{~mm}$.

The excisional biopsy showed both papillated epidermal hyperplasia with rare horn pseudocysts similar to that exhibited by seborrheic keratosis and the formation of fibroepithelial polyps (acrochordons). Similar to the prior punch and shave biopsies, HPV cytopathic changes of koilocytes, EV-like cells, and hypergranulosis with altered keratohyaline granules were identified. All of these epidermal changes occurred in the background of chronic lymphedema characterized by dermal edema, fibroplasia, dilated lymphatic vessels, and uniformly distributed stromal cells. Compared to the biopsy specimens, the papillary and upper dermis was more fibrotic. No inflammatory infiltrate was evident (fig. 3). While rare, sparse infiltrates of lymphocytes could be focally seen around vessels, none of the specimens exhibited significant perivascular or interstitial inflammatory infiltrates.

\section{Immunohistochemistry Results}

D2-40 Expression

D2-40 (antibody to podoplanin, which is expressed by lymphatic epithelium [7]) was expressed by dilated, thin-walled dermal vascular spaces mostly throughout the upper and mid-dermis (fig. 4). Dilated vessels significantly outnumbered collapsed, D2-40-positive, thin-walled dermal vessels at a ratio of 4-5 to 1 . No basal keratinocytes exhibited membranous D2-40 expression (a pattern seen in some cases of chronic lymphedema [6]). 


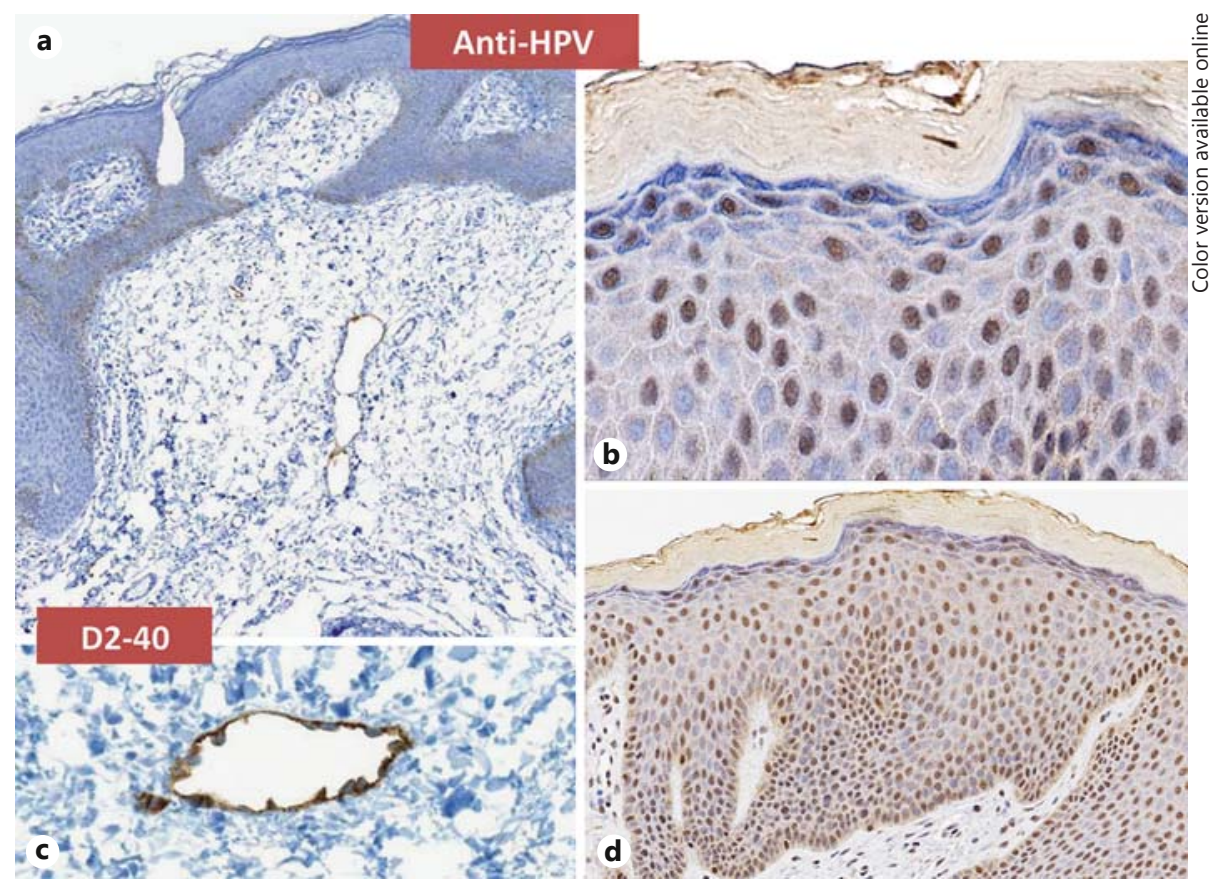

Fig. 4. a, c D2-40 expression of thin-walled, dilated vessels in an edematous background, confirming a lymphatic origin. b, d HPV capsid expression that unexpectedly demonstrated weak-to-moderate intensity in approximately half of the keratinocytic nuclei from the basal to spinous to granular layer. $\mathbf{b}$ Typical pattern of nuclear HPV capsid expression in this patient. Our findings are not considered artifacts (e.g. overstaining), because negative and positive controls showed the expected findings, not all keratinocytes expressed the capsid antigen (both regional and fractional expression rather than diffuse expression by all cells), there was a coexisting presence of HPV-associated histologies (papillated hyperplasia, koilocytes, and hypergranulosis), and multiple HPV DNAs were recovered from these specimens. d Verruca plana-like epidermal hyperplasia with widespread nuclear staining. In conventional warts, strong nuclear expression by scattered subcorneal and granular keratinocyte nuclei is the expected finding [9].

\section{Anti-HPV Antibody}

Immunohistochemical studies were performed on 5- $\mu \mathrm{m}$, formalin-fixed, paraffinembedded tissue sections using a manual method (Dako LSAB+ System-HRP, No. K0690) and a commercially available anti-HPV antibody (BPV-1/1H8 + CAMVIR, ab2417; Abcam, Cambridge, Mass., USA) [8]. The slides were deparaffinized and rehydrated using a graded alcohol series. Citrate buffer ( $\mathrm{pH}$ 6.0; Dako No. S2369) was used for antigen retrieval. The sections were incubated for 90 min with the anti-HPV antibody. This antibody is a mouse monoclonal antibody that reacts with major capsid antigen and detects HPV types 1, 6, 11, 16, 18 , and 31 in formalin-fixed, paraffin-embedded tissue $[8,9]$. With the use of appropriate negative and positive controls, all samples were tested and found to show evidence of productive HPV infection, where many keratinocytic nuclei expressed the HPV capsid antibody in the mid and lower spinous layers of the epidermis in a spotty pattern. Regionally, the percentage of nuclei labeled by the anti-HPV antibody varied from 25 to $75 \%$. The intensity of expression was mostly mild to focally moderate and accompanied by a faint blush of cytoplasmic labeling. Apart from melanophages, dermal nuclei were negative, arguing against overstaining (table 1; fig. 4). These findings are in marked contrast to those of recent studies, where a positive result indicating productive HPV infection was defined as at least 1 intensely staining keratinocyte nucleus, typically found in the granular layer [9, 10]. Many granular layer keratinocytic nuclei showed this expected finding (fig. 4). These results - in light of the 
Table 1. Numerous novel and known beta-PV genotypes detected by nested PCR assays for beta-PV and cutaneous HPV genotypes

\begin{tabular}{|c|c|c|c|c|c|c|}
\hline Sample & $\beta$-Globin & EV HPV PCR ${ }^{\mathrm{a}}$ & FAP PCR ${ }^{b}$ & $\begin{array}{l}\mathrm{PGMY} / \mathrm{GP} \\
\mathrm{PCR}^{\mathrm{c}}\end{array}$ & ISH HRGM ${ }^{\mathrm{d}}$ & IHC HPV \\
\hline Biopsy 1 & + & - & HPV25, FAIMVS16/FA162 & CTR146 ${ }^{\mathrm{f}}$ & - & + \\
\hline Biopsy 2 & + & HPV5 & $\begin{array}{l}\text { HPV119, FAIMVS13.1/ } \\
\text { FAIMVS13.2 }\end{array}$ & - & ND & + \\
\hline EXS 1 & + & - & - & - & ND & + \\
\hline EXS 2 & + & HPV5, HPV37 & HPV120, RTRX7f & - & ND & + \\
\hline EXS 3 & + & $\begin{array}{l}\text { HPV23, HPV37, } \\
\text { HPV100, DL287 }\end{array}$ & HPV49, HPV111 & - & ND & + \\
\hline EXS 4 & + & $J 7^{\mathrm{f}}$ & - & - & ND & + \\
\hline EXS 5 & + & HPV25 & HPV25, HPV49 & - & ND & + \\
\hline
\end{tabular}

EXS = Excision sample; HRGM = high-risk (oncogenic) genital mucosal alpha-PV genotypes; IHC = immunohistochemistry; ISH = in situ hybridization; ND = not done.

${ }^{a}$ EV HPV-nested PCR systems are designed to primarily detect beta-HPVs related to infections in EV patients [13].

${ }^{\mathrm{b}}$ The FAP-nested PCR system is designed to identify a broad spectrum of cutaneous HPVs [14].

c The PGMY/GP-nested PCR system is designed for the detection of HPVs primarily related to mucocutaneous lesions in the anogenital area [15].

d ISH for HRGM alpha-HPV genotypes (i.e. 16, 18, 31, 33, 35, 39, 45, 51, 52, 56, 58, and 66) [5].

e IHC for anti-HPV capsid antigen that detects HPV genotypes 1, 6, 11, 16, 18, and 31 in formalin-fixed paraffin-embedded tissue $[9,52]$.

${ }^{\mathrm{f}}$ Closest known HPV genotypes for putatively novel HPV isolates: FAIMVS13.1/FAIMVS13.2: HPV100 (87/87\%); RTRX7: HPV12 (85\%); DL287: HPV24 (74\%); J7: HPV96 (83\%); FAIMVS16/FA162: HPV96 (82/82\%); CTR146: HPV107 (86\%).

polymerase chain reaction (PCR) outlined below - indicate that this antibody is reactive with more HPV genotypes than currently recognized.

\section{Molecular Studies}

DNA Extraction from Formalin-Fixed, Paraffin-Embedded Tissue

DNA was recovered from formalin-fixed, paraffin-embedded tissue of 7 skin samples from this patient - specifically, the 2 biopsies and 5 samples of the excision specimen. These DNA samples were used for the sequencing of genes related to congenital lymphedema and EN as well as for HPV typing. The results are reported below.

\section{Lymphedema and EN Mutant Testing}

Sequencing of the GATA2 and GJC2 as well as of the HRAS and KRAS genes - known to be involved in juvenile-onset congenital lymphedema and EN, respectively $[11,12]$ - showed wild-type DNA. All coding exons of the GATA2, GJC2, and HRAS genes were amplified via PCR from DNA extracted from the sections of the 4 aforementioned formalin-fixed, paraffinembedded tissue samples. Direct sequencing of the obtained PCR products was performed using an ABI 3130XL instrument. In case of the KRAS gene, only codons 12,13, and 61 were analyzed by reverse hybridization by a KRAS 12/13/61 StripAssay Kit (ViennaLab Diagnostics GmbH, Vienna, Austria). 
Kadam et al.: Epidermal Nevus vs. Localized Elephantiasis vs. Verrucosis

\section{HPV PCR Testing}

HPV PCR products were detected by using nested EV PCR, FAP PCR, and PGMY/GP PCR systems in DNAs extracted from the sections (Puregene DNA extraction kit; Qiagen, Valencia, Calif., USA) of 4 formalin-fixed, paraffin-embedded tissue samples [13-15]. The HPV PCR products obtained from the samples were cloned and sequenced. The NCBI Basic Local Alignment Search Tool (BLAST) analysis of the sequence information obtained from the clones revealed the presence of different HPV types in the samples. Twenty HPV DNAs were identified in 6 of the 7 lesional skin samples and found to represent 15 distinct genotypes, mostly beta-PV and cutaneous HPV, and 1 putatively novel alpha-HPV genotype (table 1). Two HPV genotypes, 5 and 25, were found to persist in lesional skin for over 16 months. In the excised specimen, HPV genotypes 37 and 49 were found in 2 separate samples, suggesting a wider regional infection than for the other HPV genotypes detected.

\section{Outcome}

At the 6-month follow-up, no evidence of recurrence was found. The patient and family were lost to follow-up for 17 months, when they finally responded to a phone call requesting a follow-up visit. However, they did not follow through with this scheduled visit to the clinic and have not rescheduled any visit since.

\section{Consecutive Case Series of EN Biopsies/Excisions}

To determine whether our observation of localized lymphedema is unique to our patient or a common, but underrecognized, phenomenon in EN, we took a consecutive series of EN biopsied or excised at the Albany Medical College. Specifically, a natural language search for the clinical and/or pathologic diagnosis of 'epidermal nevus' and 'inflammatory linear verrucous epidermal nevus' was performed in the computer records from 2003 to 2013 of the Department of Pathology at the Albany Medical College. Ninety-three cases of EN were identified. Data on age, sex, site, and clinical differential diagnosis were extracted from the pathology reports. All cases were pathologically reviewed and classified according to the criteria for the subtyping of EN established by Su [16] with the addition of one more category: multiple acrochordon-like EN, which is also known as nonepidermolytic EN of a soft, papillomatous type [17]. This variant overlaps with seborrheic keratosis-like EN that additionally show multiple polypoid segments of skin with a fibrovascular core and are also covered with papillated epidermal hyperplasia. In addition to categorizing the histologic subtype of EN, the number of dilated lymphatics per square millimeter and the maximal dilation of the lymphatic vessels were measured (the methods have previously been described [18]). Statistical evaluations were performed using the statistical package Stata (Stata Corp., College Station, Tex., USA). Two EN cases were excluded because of a lack of dermis to evaluate for lymphangiectasis, leaving 91 cases for histopathologic assessment.

Overall, EN were biopsied or excised mostly from teenagers (mean/median age of 15 years), affected females and males relatively equally, and involved the head and neck more frequently than the trunk, with a minority $(<20 \%)$ affecting the extremities or anogenital region. About half were clinically diagnosed as EN, with lower numbers suspected to be melanocytic nevi, nevi sebacei, or warts (table 2). About three quarters of the EN exhibited lymphangiectasis, showed a median/mean of 1.8/1.8 lymphangiectases per square millimeter, and a median/mean maximal lymphatic dilation of $40 / 47 \mu \mathrm{m}$. These values are significantly greater than those found in normal skin in a prior study demonstrating that $50 \%$ of normal skin samples had lymphangiectases with less than 1 lymphangiectasis (0.1) per square millimeter and a mean dilation of $10 \mu \mathrm{m}$ [18]. Thus, dilated lymphatic vessels, a histologic sign of lymphostasis, are a common, but not an absolute, feature of most EN; a finding that likely correlates with the histopathologic subtype and causative mosaicism. 


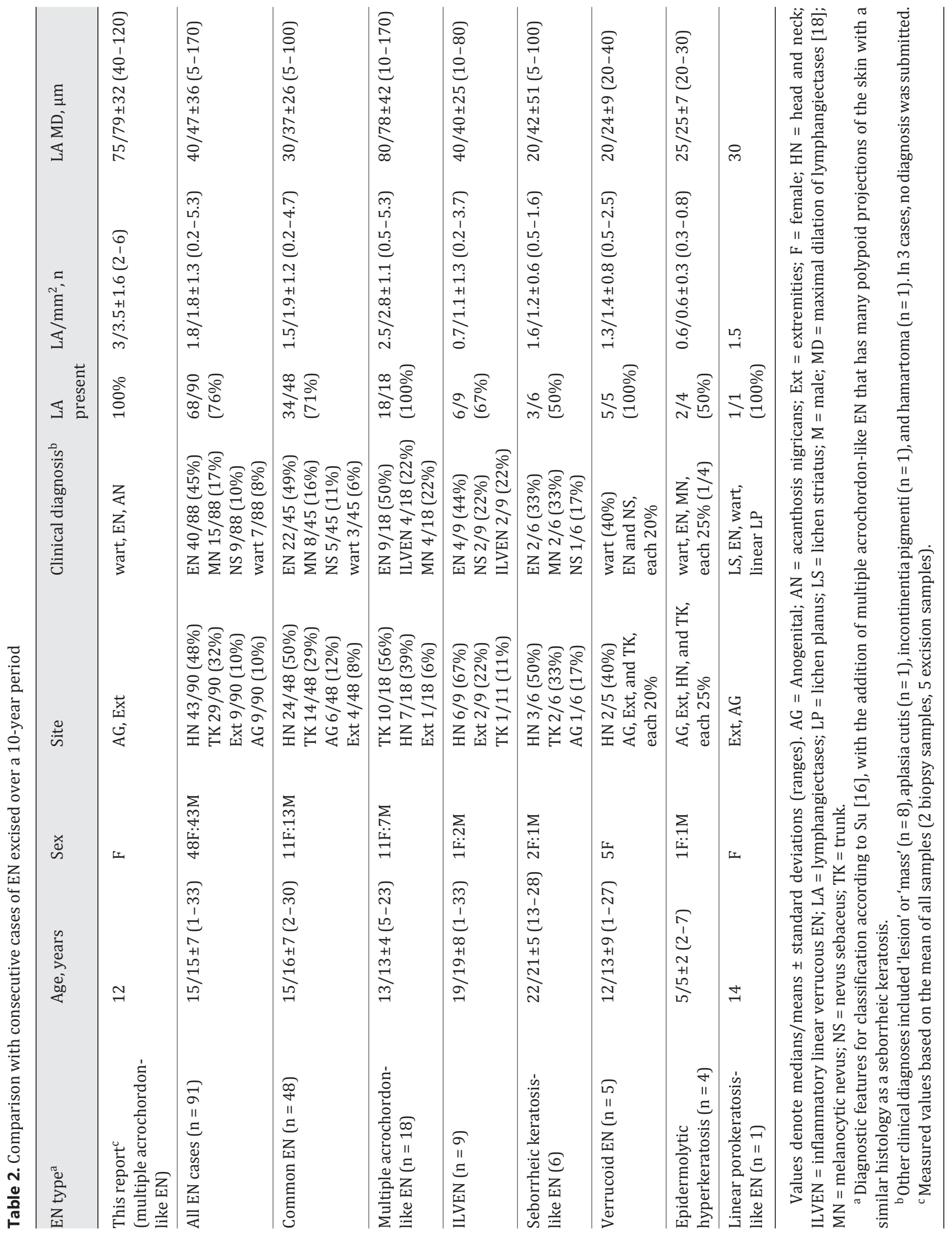




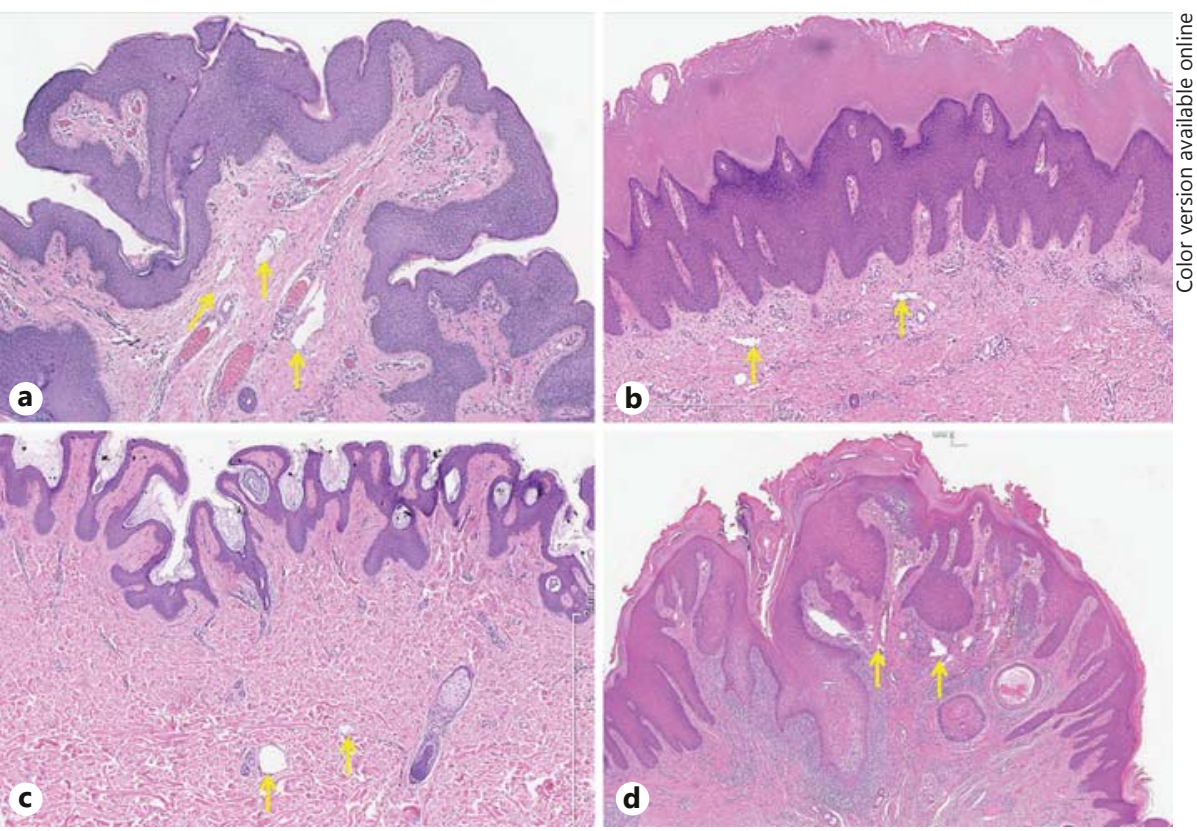

Fig. 5. Most EN are associated with underlying lymphangiectases, a surrogate marker of lymphostasis (yellow arrows marking the most overt examples) [18]. a A 5-year-old male with an acrochordon-like EN on the neck. b Common EN on the leg of a 5-year-old female. c Seborrheic keratosis-like EN on the neck of a 22-yearold female. d Inflammatory linear verrucous EN from the neck of a 16-year-old male.

Figure 5 shows examples of the major subtypes of EN associated with underlying lymphangiectases.

Comparing the findings on our patient (pooled data from biopsy and excision specimens) with all EN demonstrated significantly more lymphangiectases per square millimeter and a greater lymphatic dilation ( $p=0.004$ and $p=0.03$, respectively). However, comparing our patient with the same category of multiple acrochordon-like EN did not reveal any significant differences with respect to lymphatic measurements. Across categories, however, the differences between the subtypes were significant for age, lymphangiectases per square millimeter, and the maximal dilation of lymphatic vessels (ANOVA: $p \leq 0.002$ ). This finding is further evidence that histologic subtypes represent unique entities that likely correlate with specific mosaic (postzygotic) genomic aberrations. For example, epidermolytic hyperkeratotic EN (mean age 5 years) showed rare, barely dilated lymphatics. This would be in keeping with causative mutations affecting suprabasal keratin genes 1 or $10[19,20]$.

\section{Discussion}

Three diagnostic classifications are valid for this adolescent female's papillomatous plaque: EN, verrucosis, or localized primary elephantiasis [6, 17, 21, 22]. Vascular and lymphatic anomalies occur significantly more frequently in Schimmelpenning (EN) syndrome than in the general population (33 vs. $<1 \%$ ) [23]. Table 3 lists reports documenting lymphatic abnormalities and/or HPV infection in association with EN, demonstrating that the spectrum of findings seen in this patient is not an isolated phenomenon. Indeed, lymphangiectases (signs of lymphostasis) were found in the majority of the EN histologic subtypes (table 2). 
Table 3. Reports of EN or EN-like hyperplasia with coexisting lymphatic abnormalities and/or HPV infection

\begin{tabular}{|c|c|c|c|c|c|c|c|}
\hline $\begin{array}{l}\text { Reference } \\
\text { No. }\end{array}$ & Age, years & Sex & Site & EN type & Comorbidities & HPV genotype & $\begin{array}{l}\text { Lymphatic } \\
\text { anomalies }\end{array}$ \\
\hline 53 & 17 & $\mathrm{~F}$ & forehead & organoid nevus & $\begin{array}{l}\text { Schimmelpenning } \\
\text { syndrome }\end{array}$ & - & LM \\
\hline 54 & 5 & M & cheek & organoid nevus & $\begin{array}{l}\text { Schimmelpenning } \\
\text { syndrome }\end{array}$ & - & LM \\
\hline 55 & 10 & $\mathrm{~F}$ & back & verrucous & tissue overgrowth & - & LM \\
\hline 56 & - & $\mathrm{F} / \mathrm{M}$ & $\begin{array}{l}\text { neck, trunk, } \\
\text { or extremities }\end{array}$ & keratinocytic & Proteus syndrome & - & LM \\
\hline 57 & 11 & M & trunk & NOS & EN syndrome & - & lymphedema \\
\hline 58,59 & 21 & $\mathrm{~F}$ & arm & ichthyosiform & CHILD syndrome & AF322242 & $\begin{array}{l}\text { verruciform } \\
\text { xanthoma [60] }\end{array}$ \\
\hline 61 & NR & $2 \mathrm{M}$ & $\begin{array}{l}\text { neck, chest, } \\
\text { legs }\end{array}$ & organoid nevus & $\begin{array}{l}\text { Schimmelpenning } \\
\text { syndrome }\end{array}$ & - & LM, lymphedema \\
\hline 5 & $8 / 13$ & $2 \mathrm{~F}$ & thigh/hand & $\begin{array}{l}\text { multiple } \\
\text { acrochordon/ } \\
\text { acrokeratosis } \\
\text { verruciformis-like }\end{array}$ & none & $\begin{array}{l}16, \text { alb-1/15, } \\
16,36\end{array}$ & $\mathrm{LA}^{\mathrm{a}} /$ none \\
\hline 5 & $\begin{array}{l}\text { mean } 35 \\
(1-71)\end{array}$ & $\begin{array}{l}20 \mathrm{~F}: \\
24 \mathrm{M}\end{array}$ & head and neck & $\begin{array}{l}\text { organoid nevus } \\
\text { (nevus sebaceus) }\end{array}$ & $\begin{array}{l}\text { secondary skin } \\
\text { tumors in } 45 \% \text { of } \\
\text { cases }\end{array}$ & $82 \% \mathrm{HPV}^{\mathrm{b}}$ & $\mathrm{LA}^{\mathrm{a}}$ \\
\hline 62 & 57 & $\mathrm{~F}$ & ileostomy site & $\begin{array}{l}\text { nevus sebaceus-like } \\
\text { hyperplasia }\end{array}$ & ovarian carcinoma & 16 & scar lymphedema \\
\hline $\begin{array}{l}\text { This } \\
\text { report }\end{array}$ & 12 & $\mathrm{~F}$ & vulva & $\begin{array}{l}\text { multiple } \\
\text { acrochordon-like }\end{array}$ & none & 15 genotypes $^{c}$ & lymphedema \\
\hline
\end{tabular}

CHILD = Congenital hemidysplasia with ichthyosiform erythroderma and limb defects; F = female; LA = lymphangiectases; $\mathrm{LM}=$ lymphatic malformation; $\mathrm{M}=$ male; NOS = not otherwise specified.

${ }^{\text {a }}$ An informal review of this material revealed that LA are common.

${ }^{\mathrm{b}}$ Genital mucosal HPV types in 52\% of the cases (HPV 6, 16, and 33) and a diverse variety of EV-associated HPV types in 61\% of the cases, including well-known EV HPV types $(5,8,15,20,22,24,36-38$, and 80) and putatively novel EV HPV types (DL285, DL287, DL436, and alb-1, -2, -3, -5, -6, -7, -8, -10, -11, -12, and -13).

${ }^{\mathrm{c}}$ Genotypes 5, 23, 25, 37, 49, 100, 111, 119, 120, CTR146, DL287, FAIMVS13.1/FAIMVS13.2, FAIMS16/FA162, J7, and RTRX7.

Even though we did not identify mutant KRAS/HRAS, GJC2, or GATA2 genes in out patients' hamartoma, a mosaic gene mutation likely is present in the affected skin whose function impacts the cutaneous developmental pathway and/or lymphogenesis. The epidermal hyperplasias (e.g. papillomatosis) found in some EN, elephantiasis, and verrucosis are indistinguishable; thus, the findings of numerous and diverse HPV genotypes and phenotypic evidence of productive HPV infection are not unexpected. Lymphedema-associated immune depression likely is the pathogenic factor that links these distinct diagnoses [18, 21].

\section{Epidermal Nevus}

EN is a relatively common cutaneous mosaic disorder [17]. EN are congenital and exhibit a linear configuration that follows Blaschko's lines. In most cases, they are visible at birth or within the first years of life, but rarely late in life [24]. By their histopathologies, EN can be 
divided into an organoid type (also known as nevus sebaceus), which shows diverse aberrant adnexal hyperplasias, and keratinocytic types, which only show epidermal anomalies or hyperplasias [25].

Histopathologically, keratinocytic EN can be further categorized into many distinct types: common EN (showing hyperkeratosis, papillomatosis, acanthosis, and elongation of rete ridges), acrokeratosis verruciformis-like EN, epidermolytic hyperkeratosis, seborrheic keratosis-like EN, (psoriasiform) inflammatory linear verrucous EN, verrucoid EN, porokeratosislike EN, focal acantholytic dyskeratosis, and nevus comedonicus [16]. EN are also known as mosaic RASopathies, which are defined as the presence of at least 2 genetically distinct cell populations in the same organism, one of which is a mutant gene that affects the Ras-RafMEK-ERK signaling pathway [12]. While almost all organoid EN are the result of $H R A S>K R A S$ mosaic mutations [26], more than a third of keratinocytic EN are caused by RAS mosaic mutations and another third by FGFR3 and PIK3CA mosaic mutations [27]. A third of keratinocytic EN are wild types for the aforementioned genes that impact the Ras-Raf-MEK-ERK signaling pathway, implicating other, unknown causative genes. To date, no clinical or histologic differences have been ascribed to FGFR3, PIK3CA, and RAS mutant-related keratinocytic EN. However, epidermolytic hyperkeratotic EN and focal acantholytic dyskeratotic EN are caused by distinct, non-Ras-Raf-MEK-ERK-pathway-related genes: specifically, mutant mosaic keratin 1 or 10 genes [19, 20] and mutant mosaic ATP2A2 mutations [28], respectively. Notably, RASopathies frequently present with lymphatic anomalies including fetal nuchal edema, fetal hydrothorax, hydrops, and neonatal or postnatal lymphedema [29]. In mice, RAS genes regulate lymphangiogenesis [30], as does the RAS activation gene RAS guanyl nucleotide-releasing protein (RasGRP1) in zebra fish [31]. Thus, one of the underlying defects in EN could be aberrant lymphatic development.

\section{Primary Lymphedema}

Primary (congenital or hereditary) lymphedema occurs more frequently in women $(\leq 80 \%)$ and presents with lymphedematous swelling at birth in $10 \%$, before the age of 35 years (lymphedema praecox) in $80 \%$, and after this age (lymphedema tarda) in $10 \%$ of the cases [32]. Primary lymphedema is the result of genetic damage to key lymphangiogenesis genes [11]. These genes impact lymphogenesis, lymphatic contractility, and the structure of the lymphatic vessels. The list of genes implicated in lymphedema syndromes is growing [e.g. FLT4 (VEGFR3)/hereditary lymphedema IA (Milroy disease), GJC2/hereditary lymphedema IC, and GATA2/Emberger syndrome], but the molecular pathogenesis of many of these conditions is still poorly understood [11]. An improved, more accurate phenotypic characterization that is not restricted to age at onset, as proposed by Connell et al. [22], is expected to facilitate molecular investigations, our understanding of inheritance patterns, and the natural history of different types of primary lymphedema. For example, unilateral, segmental (localized) lymphedema is a recognized primary lymphedema phenotype and implicates a mosaic (segmental) disorder [22]. Localized lymphedema can also be acquired due to trauma, surgery, infection, and/or chronic inflammatory disorders [6]. Primary and secondary lymphedemas are associated with numerous complications including chronic inflammation, infection, fibrosis, lipogenesis, lymphangiogenesis, neoplasia, tissue hyperplasias (e.g. papillomatosis), and regional immune deficiency [11,33, 34].

Lymphedema is characterized by regional immune suppression. To trigger an effective immune response, antigen and antigen-presenting cells must travel to the lymph node. Thus, lymphatic failure causes a disruption of cell-mediated (adaptive) immunity by decreasing or obstructing immune trafficking of antigen, lymphocytes, macrophages, and dendritic/ antigen-presenting cells (Langerhans cells) to the lymph node, creating a cutaneous region of immunosuppression [35-40]. All of these abnormalities lead to a condition termed 
'lymphostatic dermopathy', which is a failure of the skin as an immune organ [41]. This immune failure could permit a latent HPV infection to progress to a productive HPV infection (warts).

\section{Verrucosis}

Warts are caused by HPV, of which there are over 100 genotypes that typically affect areas of minor trauma [42]. Most people have asymptomatic HPV infections of the normal skin, which appear to have been acquired very early in infancy, suggesting that they may be commensal [43-45]. During a lifetime, host immune factors likely inhibit the development of an overt clinical disease [43-47]. A clinically evident HPV infection presents as solitary or grouped verrucous papules and plaques with variations such as verruca plana, verruca vulgaris, myrmecia, and condyloma acuminatum, depending on the HPV genotype, location, and distribution. In immunocompetent individuals, common warts resolve due to natural immunity within months or years [42]. In contrast, (generalized) verrucosis is a diffuse, clinically recognizable HPV infection defined as a cutaneous HPV infection presenting with more than 20 lesions that are chronic and progressive, resist conventional, localized, and systemic therapies, and are associated with some form of underlying immunodeficiency [21]. Warts, immunodeficiency, lymphedema, and dysplasia (WILD) syndrome [48] is an example of generalized verrucosis associated with primary lymphedema.

Lymphangiectases are a histologic marker of decreased immune surveillance and frequently found underlying warts [18]. If the late stage of Iymphedema, i.e. elephantiasis, characterized by papillomatosis and hyperkeratosis, can be a phenomenon affecting a circumscribed region [6], then its latent (clinically silent) stage [49] could also affect a small millimeter-sized region such as that of an individual wart, where scarring due to trauma putatively facilitates clinically manifest HPV infections [18]. Clinically and microscopically, more similarities than differences exist between disseminated warts, also known as verrucosis, and the papillomatosis of elephantiasis. Indeed, the role of HPV infection in elephantiasis has not been investigated.

\section{Conclusion}

It likely is more than coincidence that our patient's EN shows lymphedema, verrucous epidermal hyperplasia, and multiple HPV DNAs. In a study of 2 keratinocytic EN and multiple organoid EN (nevus sebaceus), HPV DNA was found in the keratinocytic EN and in $82 \%$ of the organoid EN, mostly HPV type 16 and multiple beta-PV types [5]. In many cases, by PCR and in situ hybridization, an integration of HPV type 16 into the host keratinocytes was evident, implicating maternal transmission of HPV DNA and infection of an ectodermal embryologic stem cell, which explains the distribution of EN along Blaschko's lines and the presence of HPV-related histologies such as verrucous epidermal hyperplasia and koilocytosis [5]. However, recent studies which have established that postzygotic HRAS, KRAS, and MAP kinase pathway-related gene mutations are the core genetic defect in EN and EN syndromes argue against a role for HPV in these mosaic RASopathies [12, 26, 27, 50, 51]. Nonetheless, the epidermal hyperplasias found in elephantiasis, EN (keratinocytic and organoid types), and verrucosis are strikingly similar $[5,6,21]$. These overlaps suggest that mutant HRAS and KRAS are insufficient in themselves to produce the diversity of clinical and pathologic morphologies found in EN. Considering that lymphatic anomalies are a clinical phenotype of RASopathies [29] and our finding that most keratinocytic EN show lymphangiectases, EN may be localized sites of lymph-related immunodeficiency that permit a latent HPV infection to progress to verrucosis, i.e. a clinically manifest HPV infection. 


\section{Acknowledgements}

This case study was supported in part by clinical revenues and generous donations to the Divisions of Dermatology and Dermatopathology, Department of Pathology, Albany Medical College.

\section{Disclosure Statement}

The authors have no conflicts of interest to disclose.

\section{References}

1 Meisels A, Fortin R: Condylomatous lesions of the cervix and vagina. I. Cytologic patterns. Acta Cytol 1976;20: 505-509.

2 Corbalan-Velez R, Ruiz-Macia JA, Brufau C, Lopez-Lozano JM, Martinez-Barba E, Martinez-Escribano J, et al: Epidermodysplasia verruciformis-like cells as histologic markers of immunosuppression: review of 229 squamous cell carcinomas (in Spanish). Actas Dermosifiliogr 2008;99:269-274.

-3 Morrison C, Eliezri Y, Magro C, Nuovo GJ: The histologic spectrum of epidermodysplasia verruciformis in transplant and AIDS patients. J Cutan Pathol 2002;29:480-489.

4 Weedon D: Viral diseases: Papovaviridae (Papillomaviridae); in Weedon D (ed): Weedon's Skin Pathology, ed 3. Philadelphia, Churchill Livingstone (Elsevier), 2010, pp 619-625.

5 Carlson JA, Cribier B, Nuovo G, Rohwedder A: Epidermodysplasia verruciformis-associated and genitalmucosal high-risk human papillomavirus DNA are prevalent in nevus sebaceus of Jadassohn. J Am Acad Dermatol 2008;59:279-294.

6 Lu S, Tran TA, Jones DM, Meyer DR, Ross JS, Fisher HA, et al: Localized lymphedema (elephantiasis): a case series and review of the literature. J Cutan Pathol 2009;36:1-20.

7 Gomaa AH, Yaar M, Bhawan J: Cutaneous immunoreactivity of D2-40 antibody beyond the lymphatics. Am J Dermatopathol 2007;29:18-21.

8 Abcam $^{\circledR}$ : Anti-HPV antibody [BPV-1/1H8 + CAMVIR] (ab2417). http://www.abcam.com/HPV-antibody-BPV1-1H8-CAMVIR-ab2417.html (accessed 7/12/2013).

-9 Wititsuwannakul J, Klump VR Jr, McNiff JM, Ko CJ: Detecting HPV in cutaneous lesions using anti-HPV antibody immunohistochemistry. Am J Dermatopathol 2013;35:327-331.

10 Jenson AB, Geyer S, Sundberg JP, Ghim S: Human papillomavirus and skin cancer. J Investig Dermatol Symp Proc 2001;6:203-206.

11 Alitalo K: The lymphatic vasculature in disease. Nat Med 2011;17:1371-1380.

12 Hafner C, Groesser L: Mosaic RASopathies. Cell Cycle 2013;12:43-50.

13 Fuessel Haws AL, He Q, Rady PL, Zhang L, Grady J, Hughes TK, et al: Nested PCR with the PGMY09/11 and $\mathrm{GP}^{+} / 6^{+}$primer sets improves detection of HPV DNA in cervical samples. J Virol Methods 2004;122:87-93.

-14 Harwood CA, Spink PJ, Surentheran T, Leigh IM, de Villiers EM, McGregor JM, et al: Degenerate and nested PCR: a highly sensitive and specific method for detection of human papillomavirus infection in cutaneous warts. J Clin Microbiol 1999;37:3545-3555.

15 Forslund 0, Ly H, Higgins G: Improved detection of cutaneous human papillomavirus DNA by single tube nested 'hanging droplet' PCR. J Virol Methods 2003;110:129-136.

16 Su WP: Histopathologic varieties of epidermal nevus. A study of 160 cases. Am J Dermatopathol 1982;4:161170.

17 Happle R, Rogers M: Epidermal nevi. Adv Dermatol 2002;18:175-201.

-18 Paul J, Carlson JA: Lymphangiectases are common underlying warts and in normal peritumoral skin: histologic evidence of decreased immune surveillance. Am J Dermatopathol 2011;33:152-160.

19 Paller AS, Syder AJ, Chan YM, Yu QC, Hutton E, Tadini G, et al: Genetic and clinical mosaicism in a type of epidermal nevus. N Engl J Med 1994;331:1408-1415.

20 Tsubota A, Akiyama M, Sakai K, Goto M, Nomura Y, Ando S, et al: Keratin 1 gene mutation detected in epidermal nevus with epidermolytic hyperkeratosis. J Invest Dermatol 2007;127:1371-1374.

21 Sri JC, Dubina MI, Kao GF, Rady PL, Tyring SK, Gaspari AA: Generalized verrucosis: a review of the associated diseases, evaluation, and treatments. J Am Acad Dermatol 2012;66:292-311.

-22 Connell F, Brice G, Jeffery S, Keeley V, Mortimer P, Mansour S: A new classification system for primary lymphatic dysplasias based on phenotype. Clin Genet 2010;77:438-452.

23 Greene AK, Burrows PE, Smith L, Mulliken JB: Periorbital lymphatic malformation: clinical course and management in 42 patients. Plast Reconstr Surg 2005;115:22-30. 
24 Kim R, Marmon S, Kaplan J, Kamino H, Pomeranz MK: Verrucous epidermal nevus. Dermatol Online J 2013;19: 20707.

25 Happle R: The group of epidermal nevus syndromes. Part I. Well defined phenotypes. J Am Acad Dermatol 2010;63:1-22; quiz 23-24.

-26 Groesser L, Herschberger E, Ruetten A, Ruivenkamp C, Lopriore E, Zutt M, et al: Postzygotic HRAS and KRAS mutations cause nevus sebaceous and Schimmelpenning syndrome. Nat Genet 2012;44:783-787.

27 Hafner C, Toll A, Gantner S, Mauerer A, Lurkin I, Acquadro F, et al: Keratinocytic epidermal nevi are associated with mosaic RAS mutations. J Med Genet 2012;49:249-253.

28 Sakuntabhai A, Dhitavat J, Burge S, Hovnanian A: Mosaicism for ATP2A2 mutations causes segmental Darier's disease. J Invest Dermatol 2000;115:1144-1147.

-29 Zenker M: Clinical manifestations of mutations in RAS and related intracellular signal transduction factors. Curr Opin Pediatr 2011;23:443-451.

-30 Ichise T, Yoshida N, Ichise H: H-, N- and Kras cooperatively regulate lymphatic vessel growth by modulating VEGFR3 expression in lymphatic endothelial cells in mice. Development 2010;137:1003-1013.

-31 Huang H, Jin T, Wang L, Wang F, Zhang R, Pan Y, et al: The RAS guanyl nucleotide-releasing protein RasGRP1 is involved in lymphatic development in zebrafish. J Biol Chem 2013;288:2355-2364.

-32 Harwood CA, Mortimer PS: Causes and clinical manifestations of lymphatic failure. Clin Dermatol 1995;13: $459-471$.

-33 Saito Y, Nakagami H, Kaneda Y, Morishita R: Lymphedema and therapeutic lymphangiogenesis. Biomed Res Int 2013;2013:804675.

34 Schneider M, Conway EM, Carmeliet P: Lymph makes you fat. Nat Genet 2005;37:1023-1024.

-35 Mallon E, Powell S, Mortimer P, Ryan TJ: Evidence for altered cell-mediated immunity in postmastectomy lymphoedema. Br J Dermatol 1997;137:928-933.

-36 Stark R, Dwyer E, De Forest M: Effect of surgical ablation of regional lymph nodes on survival of skin homografts. Ann NY Acad Sci 1960;87:140-148.

-37 Lambert PB, Frank HA, Bellman S, Farnsworth D: The role of the lymph trunks in the response to allogeneic skin transplants. Transplantation 1965;3:62-73.

-38 Yin N, Zhang N, Lal G, Xu J, Yan M, Ding Y, et al: Lymphangiogenesis is required for pancreatic islet inflammation and diabetes. PLoS One 2011;6:e28023.

39 Skobe M, Dana R: Blocking the path of lymphatic vessels. Nat Med 2009;15:993-994.

40 Bordea C, Wojnarowska F, Morris PJ: Multiple cutaneous malignancies arising in limbs with signs of lymphatic insufficiency in transplant patients. Br J Plast Surg 1999;52:619-622.

41 Földi E, Földi M: Földi's Textbook of Lymphology. Munich, Elsevier, 2006.

42 Nai-Ming L, Yuk-Ming William T: Warts (non-genital). Clin Evid (Online) 2007;2007:1710.

43 Antonsson A, Karanfilovska S, Lindqvist PG, Hansson BG: General acquisition of human papillomavirus infections of skin occurs in early infancy. J Clin Microbiol 2003;41:2509-2514.

44 Antonsson A, Erfurt C, Hazard K, Holmgren V, Simon M, Kataoka A, et al: Prevalence and type spectrum of human papillomaviruses in healthy skin samples collected in three continents. J Gen Virol 2003;84:18811886.

45 Antonsson A, Forslund O, Ekberg H, Sterner G, Hansson BG: The ubiquity and impressive genomic diversity of human skin papillomaviruses suggest a commensalic nature of these viruses. J Virol 2000;74:11636-11641.

46 de Villiers EM, Lavergne D, McLaren K, Benton EC: Prevailing papillomavirus types in non-melanoma carcinomas of the skin in renal allograft recipients. Int J Cancer 1997;73:356-361.

47 Broker TR, Jin G, Croom-Rivers A, Bragg SM, Richardson M, Chow LT, et al: Viral latency: the papillomavirus model. Dev Biol (Basel) 2001;106:443-451; discussion 452-453, 465-475.

-48 Kreuter A, Hochdorfer B, Brockmeyer NH, Altmeyer P, Pfister H, Wieland U: A human papillomavirus-associated disease with disseminated warts, depressed cell-mediated immunity, primary lymphedema, and anogenital dysplasia: WILD syndrome. Arch Dermatol 2008;144:366-372.

49 Warren AG, Brorson H, Borud LJ, Slavin SA: Lymphedema: a comprehensive review. Ann Plast Surg 2007;59: 464-472.

50 Sun BK, Saggini A, Sarin KY, Kim J, Benjamin L, LeBoit PE, et al: Mosaic activating RAS mutations in nevus sebaceus and nevus sebaceus syndrome. J Invest Dermatol 2013;133:824-827.

51 Levinsohn JL, Tian LC, Boyden LM, McNiff JM, Narayan D, Loring ES, et al: Whole-exome sequencing reveals somatic mutations in HRAS and KRAS, which cause nevus sebaceus. J Invest Dermatol 2013;133:827-830.

52 Calvert RJ, Smith E: Metastatic acropachy in lymphatic leukemia. Blood 1955;10:545-549.

53 Schimmelpenning GW: Clinical contribution to symptomatology of phacomatosis (in German). Fortschr Geb Rontgenstr Nuklearmed 1957;87:716-720.

-54 Seawright AA, Sullivan TJ, Pelekanos JT, Masel J: Coexistent orbital and cerebellar venous anomalies in linear sebaceous naevus syndrome. Aust NZ J Ophthalmol 1996;24:373-376.

55 Hennekam RC, Kwa VI, van Amerongen A: Arteriovenous and lymphatic malformations, linear verrucous epidermal nevus and mild overgrowth: another hamartoneoplastic syndrome? Clin Dysmorphol 1999;8:111115.

56 Nguyen D, Turner JT, Olsen C, Biesecker LG, Darling TN: Cutaneous manifestations of Proteus syndrome: correlations with general clinical severity. Arch Dermatol 2004;140:947-953. 
57 Neumann LM, Scheer I, Kunze J, Stöver B: Cerebral manifestations, hemihypertrophy and lymphoedema of one leg in a child with epidermal nevus syndrome (Schimmelpenning-Feuerstein-Mims). Pediatr Radiol 2003;33: 637-640.

58 Rohwedder A, Murphy M, Carlson FA: Multiple human papillomavirus DNA identified in verruciform xanthoma by nested polymerase chain reaction with degenerate consensus primers. J Cutan Pathol 2003;30:344-346; author reply 347.

59 Carlson JA, Rohwedder A, Dolph J, Murphy M: Hypothesis: lymphatic obstruction in combination with infection by human papillomavirus is responsible for development of verruciform xanthoma. Dermatopathol Pract Concept 2003;9:e1-e12.

-60 Lu S, Rohwedder A, Murphy M, Carlson JA: Verruciform xanthoma: localized lymphedema (elephantiasis) is an essential pathogenic factor. J Cutan Pathol 2012;39:391-394.

61 Greene AK, Rogers GF, Mulliken JB: Schimmelpenning syndrome: an association with vascular anomalies. Cleft Palate Craniofac J 2007;44:208-215.

-62 Raghu P, Tran TA, Rady P, Tyring S, Carlson JA: Ileostomy-associated chronic papillomatous dermatitis showing nevus sebaceous-like hyperplasia, HPV 16 infection, and lymphedema: a case report and literature review of ostomy-associated reactive epidermal hyperplasias. Am J Dermatopathol 2012;34:e97e102. 